\title{
In Situ Formation of Ag Capping Layer for Preventing Oxidation in Copper Chemical Mechanical Polishing
}

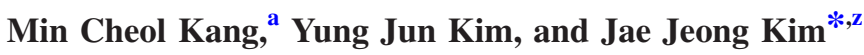

School of Chemical and Biological Engineering, Seoul National University, Seoul 151-742, Korea

\begin{abstract}
An Ag capping layer as a metal barrier was proposed to hinder the oxide formation of $\mathrm{Cu}$, which is exposed after chemical mechanical polishing (CMP). To simplify the process step, the in situ formation of the Ag barrier during the Cu CMP process was investigated using a displacement reaction at either the second step of Cu CMP or the buffing step. The Ag capping layer effectively disturbed the contact between oxygen and $\mathrm{Cu}$, which led to preventing $\mathrm{Cu}$ oxidation. Moreover, through the capping formation at the buffing step, the depth of dishing was diminished to about $20 \mathrm{~nm}$ regardless of the linewidth. (C) 2009 The Electrochemical Society. [DOI: 10.1149/1.3159828] All rights reserved.
\end{abstract}

Manuscript submitted April 10, 2009; revised manuscript received May 13, 2009. Published July 1, 2009.

The introduction of the damascene process based on chemical mechanical polishing (CMP) enables the multilayer metallization. Copper $(\mathrm{Cu})$ has replaced tungsten $(\mathrm{W})$ and aluminum $(\mathrm{Al})$ as an interconnection material due to its comparatively low electrical resistance and good resistance to electromigration. ${ }^{1-3}$ In the damascene process, the $\mathrm{Cu}$ interconnection is formed by $\mathrm{CMP}$, which is used to remove excessively electroplated $\mathrm{Cu}$ during electroplating. The top surface of the $\mathrm{Cu}$ is exposed to the atmosphere during the $\mathrm{CMP}$. This exposed $\mathrm{Cu}$ layer is easily oxidized. It continues to oxidize because $\mathrm{Cu}$ cannot form a passivated layer like other materials such as $\mathrm{W}$ and $\mathrm{Al}$. Because the $\mathrm{Cu}$ oxide has a higher resistivity than pure $\mathrm{Cu}$, the overall resistivity of interconnection increased. Therefore, to achieve a reliable $\mathrm{Cu}$ interconnection in the damascene process, it is important to prevent $\mathrm{Cu}$ oxidation.

Presently, a $\mathrm{Si}_{3} \mathrm{~N}_{4}$ film is deposited as a barrier layer. Various methods to prevent $\mathrm{Cu}$ oxidation have been attempted, including ion implantation ${ }^{4,5}$ and silicide formation, ${ }^{6}$ where the top surface of $\mathrm{Cu}$ reacted with boron ions or $\mathrm{SiH}_{4}$. Recently, some research has been exploring the selective deposition of CoWP or CoWB, which acts as barrier layer, onto the exposed $\mathrm{Cu}$ surface through electroless plating. ${ }^{7,8}$ All these methods are effective in preventing $\mathrm{Cu}$ oxidation; however, the aforementioned methods must be conducted after the CMP. Also, $\mathrm{Cu}$ oxidation could be prevented effectively through the codeposition of magnesium $(\mathrm{Mg}$, several atom percent) into $\mathrm{Cu}$. Although the resistance of $\mathrm{Cu}$ decreased when applying the annealing process to diffuse $\mathrm{Mg}$ to the $\mathrm{Cu}$ surface to form $\mathrm{Mg}$ oxide as a passivation layer on $\mathrm{Cu}$, the resistance increased as $\mathrm{Mg}$ concentrations increased. 9,10

Kim et al. showed that an $\mathrm{Ag}$ film formed on a $\mathrm{Cu}$ surface after $\mathrm{Cu}$ electroplating is effective in preventing $\mathrm{Cu}$ oxidation. ${ }^{11}$ Moreover, the resistance might not increase even though the $\mathrm{Ag}$ layer is formed onto the $\mathrm{Cu}$ surface because the resistivity of $\mathrm{Ag}$ is lower than that of $\mathrm{Cu}$. In this study, a method of forming an $\mathrm{Ag}$ capping layer during the CMP process was investigated without the additional process.

\section{Experimental}

The structure of the wafer used in this study was $\mathrm{Cu}[9000 \AA$,

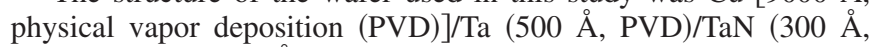
$\mathrm{PVD}) / \mathrm{SiO}_{2}(10,000 \AA$, thermal oxidation)/Si. Cu CMP consists of three steps; at the first step of CMP, overdeposited $\mathrm{Cu}$ was removed using alumina-based slurry. The slurry for the first step CMP consisted of $2 \mathrm{wt} \% \mathrm{H}_{2} \mathrm{O}_{2}, 0.02 \mathrm{M}$ citric acid, and $0.01 \mathrm{M}$ 5 -aminotetrazole (ATRA), ${ }^{12}$ which were used as an oxidizing agent, a complexing agent, and a corrosion inhibitor, respectively. At the second step of CMP, residual $\mathrm{Cu}$ and the barrier layer were removed using a colloidal silica-based slurry with an abrasive size of $50 \mathrm{~nm}$.

\footnotetext{
* Electrochemical Society Active Member.

a Present address: Hynix Semiconductor Inc., Advanced Process Research and Development Division, Icheon 467-701, Korea.

${ }^{z}$ E-mail: jjkimm@snu.ac.kr
}

The slurry for the second step CMP consisted of 1 wt $\% \mathrm{H}_{2} \mathrm{O}_{2}, 0.02$ $\mathrm{M}$ glycine as a complexing agent, and $0.01 \mathrm{M}$ ATRA. At the third step, the buffing step removed residual slurry on the polished wafer using deionized water preferentially before a postcleaning process to prevent brush contamination. The formation of the Ag capping layer on the $\mathrm{Cu}$ surface was attempted; either the slurry in the second step of CMP or the solution in the buffing step contained $0.01 \mathrm{M} \mathrm{Ag}$ ions. The $\mathrm{Cu}$ wafer was polished using the R\&D CMP machine POLI-500 (G\&P Technology, Korea). This polisher is composed of a 20 in. platen and a 4 in. carrier with the listed polishing and buffing conditions (Table I). The oxidation process was carried out in an atmospheric condition in a horizontal quartz tube furnace by feeding compressed air continuously after filtration of oil impurity and moisture. The pressure inside the tube was kept at 1 atm by controlling the flow rate of air and the pumping valve.

\section{Results and Discussion}

A displacement reaction occurred spontaneously because the reduction potential of $\mathrm{Ag}[0.799 \mathrm{~V}$ vs normal hydrogen electrode (NHE)] is higher by $0.460 \mathrm{~V}$ compared to $\mathrm{Cu}(0.339 \mathrm{~V}$ vs NHE) (Eq. 1). The displacement reaction results in the formation of an $\mathrm{Ag}$ film on the $\mathrm{Cu}$ surface

$$
\mathrm{Cu}+2 \mathrm{Ag}^{+} \rightarrow \mathrm{Cu}^{2+}+2 \mathrm{Ag}
$$

$\mathrm{Cu}$ CMP was conducted with two consecutive polishing steps, where bulk $\mathrm{Cu}$ at the first step or residual $\mathrm{Cu}$, the barrier layer, and the dielectric layer were removed sequentially, and at the buffing step residual slurry was removed on the polished wafer. In this study, to minimize loss of the $\mathrm{Ag}$ capping layer, the displacement reaction was applied to the second step of CMP or to the buffing step.

The color of the $\mathrm{Cu}$ surface changed from coppery to silvery using the Ag-ion-based slurry, indicating the selective formation of an Ag-like layer on the $\mathrm{Cu}$ surface (Fig. 1a). X-ray diffraction (XRD) and Auger electron spectroscopy (AES) depth profile analyses were performed to examine a polished $\mathrm{Cu}$ surface. As shown in Fig. 1b, the Ag peak, which was attributed to the (111) texture, was observed on the surface polished by the Ag-ion-based slurry. An analysis of the AES depth profile confirmed that the Ag layer, derived from the displacement reaction, was formed restrictively on the $\mathrm{Cu}$ surface (Fig. 1c). The sheet resistances of $\mathrm{Cu}$ with the $\mathrm{Ag}$

\begin{tabular}{|c|c|c|c|}
\hline Conditions & $\begin{array}{l}\text { First step } \\
\text { of CMP }\end{array}$ & $\begin{array}{l}\text { Second step } \\
\text { of CMP }\end{array}$ & $\begin{array}{c}\text { Buffing } \\
\text { step }\end{array}$ \\
\hline Applied pressure (psi) & 2.5 & 1.5 & 1.5 \\
\hline Platen speed (rpm) & 80 & 93 & 60 \\
\hline Head speed (rpm) & 75 & 87 & 60 \\
\hline Slurry flow rate $(\mathrm{mL} / \mathrm{min})$ & & 150 & \\
\hline
\end{tabular}




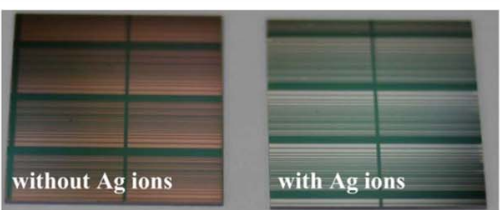

(a)

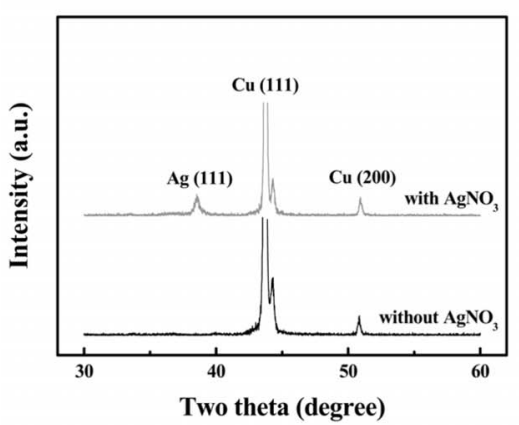

(b)

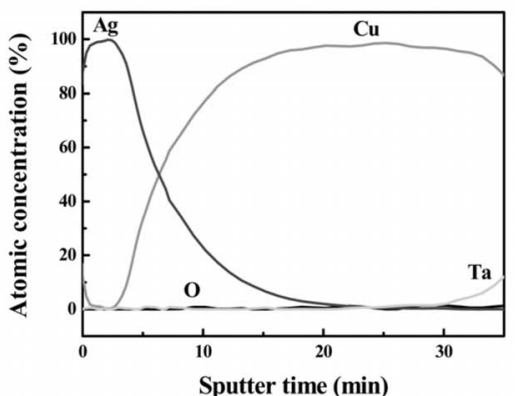

(c)

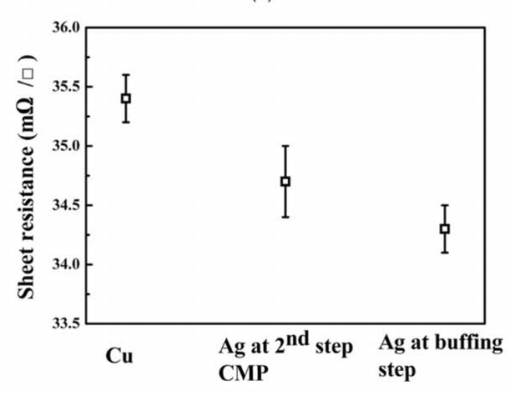

(d)

Figure 1. (Color online) Characteristics of polished wafer after second step of CMP using slurry with and without $\mathrm{AgNO}_{3}$; (a) photo images, (b) XRD spectra, (c) AES depth profile, and (d) sheet resistance.

capping layer, which is formed at the second step of CMP or the buffing step, were reduced by 2 and 3\%, respectively. The thickness of $\mathrm{Ag}$ on $\mathrm{Cu}$ could not be measured through field-emission-scanning electron microscopy (FESEM) because the boundary between Ag and $\mathrm{Cu}$ was not clear. According to a previous study, the thickness of $\mathrm{Ag}$ was around $40 \mathrm{~nm}$ when electroplated $\mathrm{Cu}$ was dipped into the Ag-based solution.

When reducing an ionized metal with a higher reduction potential, the substrate generally dissolves to provide an electron during the displacement reaction. Table II shows the values of root-meansquare (rms) roughness for a $\mathrm{Cu}$ surface immersed in an Ag-ionbased slurry and for a polished surface following the second step of CMP or the buffing step with and without Ag ions. The rms roughness of the $\mathrm{Cu}$ wafer just immersed into a slurry containing $0.01 \mathrm{M}$ $\mathrm{Ag}$ ions for $30 \mathrm{~s}$ increased from about 7 to about $13 \mathrm{~nm}$, resulting from the dissolution of the $\mathrm{Cu}$ surface. However, there was no significant difference in the rms roughness of the $\mathrm{Cu}$ wafers when they
Table II. The rms roughness of $\mathrm{Cu}$ in various solutions.

\begin{tabular}{lc} 
Conditions & $\begin{array}{c}\text { RMS roughness } \\
(\mathrm{nm})\end{array}$ \\
\hline $\begin{array}{l}\text { As-prepared } \mathrm{Cu} \\
\text { Immersed surface in slurry containing }\end{array}$ & 7.2 \\
$0.01 \mathrm{M}$ Ag ions for $30 \mathrm{~s}$ & 13.6 \\
Polished surface after second step & \\
CMP without $0.01 \mathrm{M} \mathrm{Ag}$ ions & 0.9 \\
Polished surface after second step & \\
CMP with $0.01 \mathrm{M}$ Ag ions & 1.1 \\
Surface after buffing step with $0.01 \mathrm{M}$ Ag ions & 1.7
\end{tabular}

were polished using the slurry with and without $\mathrm{Ag}$ ions because the mechanical abrasion during the polishing outweighed that of $\mathrm{Cu}$ dissolution. When the Ag-ion-based solution was used at the buffing step, the rms roughness was about $1.7 \mathrm{~nm}$. Regarding surface roughness, the Ag capping layers, which were formed at the second step of CMP or at the buffing step, were more favorably compared with a $\mathrm{Cu}$ wafer dipped into an Ag-based solution. The larger roughness of the Ag film just after dipping into the slurry with $\mathrm{Ag}$ ions may originate from the complex chemical reactions, including the oxidation of the $\mathrm{Cu}$ surface, the continuous corrosion of copper during the $\mathrm{Ag}$ displacement reaction, etc. The slurry contains a strong oxidizing agent such as hydrogen peroxide, which can cause the oxidation of the $\mathrm{Cu}$ surface. The oxidized surface may block the replacement reaction that induced nonuniform $\mathrm{Ag}$ deposition, and the oxidized surface could generate some defects on the surface. All these effects would be the reason for the rough surface after the dipping in the slurry. Compared to that, the buffing step includes the application of mechanical forces to the wafer by contact with a polishing pad, and the addition of $\mathrm{Ag}$ ion during the buffing step has a simple chemical reaction pathway (just displacement between $\mathrm{Ag}$ and $\mathrm{Cu}$ ). Furthermore, the strong stream of solution during the buffing step with applied pressure by a polishing pad may lead to an excellent redistribution of $\mathrm{Ag}$ or $\mathrm{Cu}$ ions (generated during the dissolution of $\mathrm{Cu}$ ), which ensures a good uniformity and low surface defect generation.

To investigate the oxidation resistance of the $\mathrm{Cu}$ wafer with the Ag capping layer, an oxidation experiment was performed at $300^{\circ} \mathrm{C}$ for various oxidation times. The resulting changes in sheet resistance are presented in Fig. 2. In a pure-Cu wafer, the sheet resistance of $\mathrm{Cu}$ dramatically increased after oxidation. For example, the sheet resistance of the $\mathrm{Cu}$ wafer without an $\mathrm{Ag}$ capping layer, which was oxidized for $30 \mathrm{~min}$, increased by 5000 times. In the AES depth profile after oxidation (Fig. 3a), oxygen can be distinctly observed throughout the $\mathrm{Cu}$ layer. This means that a complete $\mathrm{Cu}$ oxidation caused an increase in sheet resistance. However, for the $\mathrm{Ag}$ capping layer onto the $\mathrm{Cu}$ wafer, there was no significant difference in the

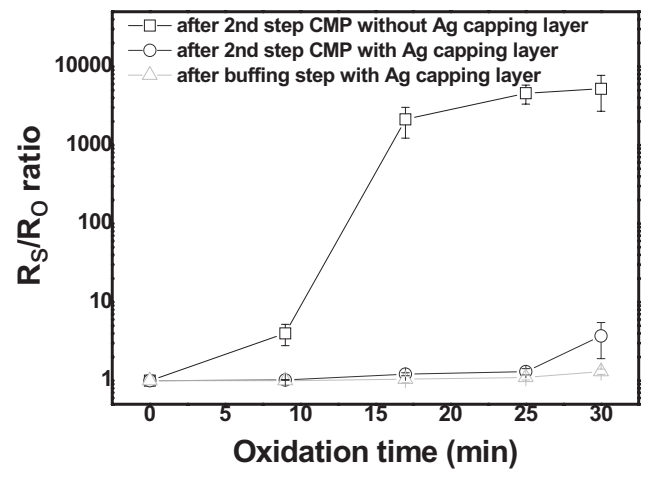

Figure 2. Change in sheet resistance of polished wafer using slurry with and without $0.01 \mathrm{M} \mathrm{Ag}$ ions before $\left(R_{\mathrm{O}}\right)$ and after $\left(R_{\mathrm{S}}\right)$ various oxidation times at $300^{\circ} \mathrm{C}$ atmospheric conditions. 


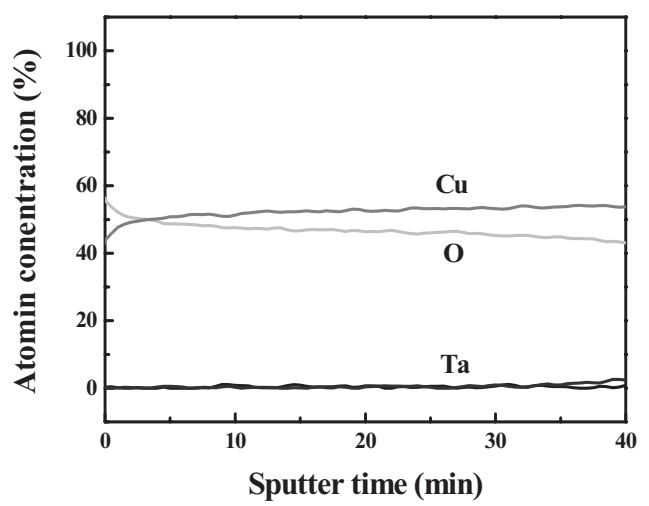

(a)

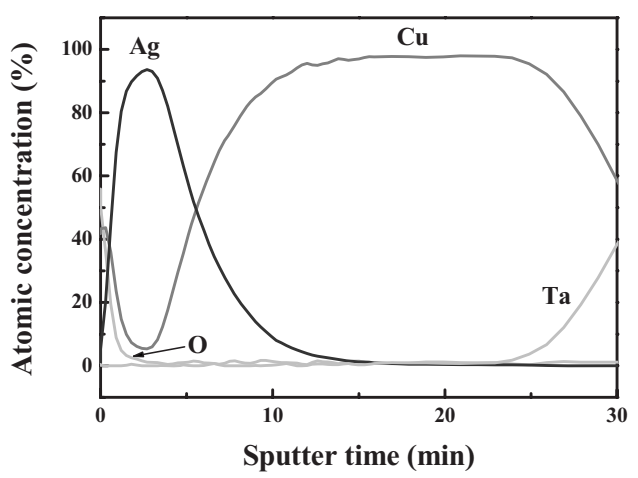

(b)

Figure 3. AES depth profiles of polished wafer after 25 min oxidation at $30{ }^{\circ} \mathrm{C}$ atmospheric condition; (a) without and (b) with Ag capping layer.

change in the sheet resistance before and after oxidation, which indicated that the Ag capping layer effectively hindered the contact between oxygen and $\mathrm{Cu}$ (Fig. $3 \mathrm{~b}$ ). The increase in the sheet resistance of the Ag capping layer might be from the oxidation of $\mathrm{Cu}: \mathrm{Ag}$ capping decelerates the diffusion of $\mathrm{Cu}$ onto the surface; it does not block the diffusion completely above $300^{\circ} \mathrm{C}$. It consumes the copper under the capping layer and also induces the increase in sheet resistance. The formation of a thin oxide layer at the surface after $30 \mathrm{~min}$ of oxidation at $300^{\circ} \mathrm{C}$ is observed at the surface of the Ag capping layer in Fig. 3b.

The previous oxidation test showed that the $\mathrm{Cu}$ wafer with the Ag capping layer tolerated the oxidation thermal budget of $30 \mathrm{~min}$ at $350^{\circ} \mathrm{C}$. Figure 4 shows the oxidation resistance of the $\mathrm{Ag}$ capping layer after exposure to various oxidation temperatures for $30 \mathrm{~min}$.

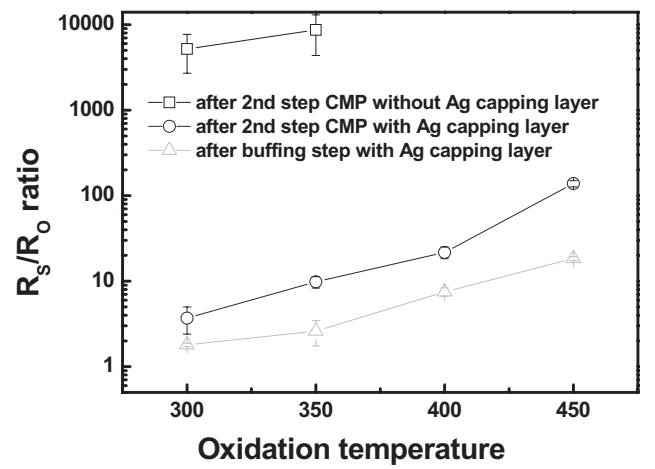

Figure 4. Change in sheet resistance of polished wafer using slurry with and without $0.01 \mathrm{M} \mathrm{Ag}$ ions before $\left(R_{\mathrm{O}}\right)$ and after $\left(R_{\mathrm{S}}\right)$ various oxidation temperatures for $30 \mathrm{~min}$.

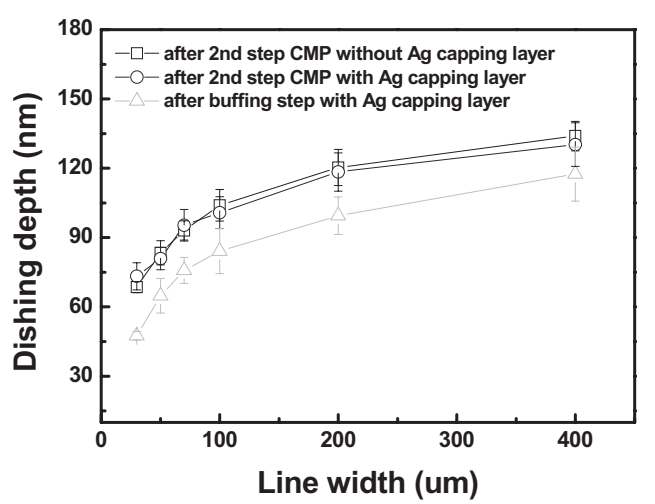

Figure 5. Dishing results measured by alpha step at wide metal line of various widths.

For the $\mathrm{Cu}$ wafer without the $\mathrm{Ag}$ capping layer, the sheet resistance could not be measured due to complete oxidation of the $\mathrm{Cu}$ wafer above $400^{\circ} \mathrm{C}$, whereas with the $\mathrm{Ag}$ capping layer, an increase in the sheet resistance was observed as the oxidation temperature increased. At the maximum oxidation temperature $\left(450^{\circ} \mathrm{C}\right)$ used in this study, the sheet resistance of the $\mathrm{Cu}$ wafer with the $\mathrm{Ag}$ capping layers formed at the second step of CMP and at the buffing step increased about 140 and 20 times, respectively. The $\mathrm{Cu}$ wafer showed a better resistance against oxidation when the Ag capping layer was formed at the buffing step, which seemed to be contributed by the thicker Ag formation due to the CMP process mechanism.

The in situ formation of the Ag capping layer also plays an important role in decreasing the dishing during the CMP process. $\mathrm{Cu}$ dishing refers to the loss of $\mathrm{Cu}$ during the CMP process, often caused by the deformation of the pad and additives in the slurry. Several solutions have been proposed to overcome this problem, such as the insertion of a dummy pattern on the wafer or the addition of a passivation agent into the slurry. ${ }^{13,14}$ Although these methods can reduce the amount of $\mathrm{Cu}$ dishing when applying the aforementioned methods, the $\mathrm{Cu}$ dishing inevitably occurs in the overpolishing step, where residual copper and the barrier layer on the dielectric layer are to be removed completely.

The variation in the $\mathrm{Cu}$ dishing according to pattern width after CMP is shown in Fig. 5. Using the Ag-ion-based solution in the buffing step, the depth of $\mathrm{Cu}$ dishing was reduced by $20-30 \mathrm{~nm}$ regardless of the linewidth. When $\mathrm{Cu}$ was consumed to generate electrons to $\mathrm{Ag}$ ions, the amount of the formed $\mathrm{Ag}$ layer was about 2.26 times larger than that of the consumed $\mathrm{Cu}$ layer. Based on the reaction stoichiometry and lattice parameters $(\mathrm{Cu}$ and $\mathrm{Ag}$ were 361.69 and $408.53 \mathrm{pm}$, respectively), the calculated thickness of the formed $\mathrm{Ag}$ layer and the consumed $\mathrm{Cu}$ layer was 34 and $15 \mathrm{~nm}$, respectively. Therefore, the final thickness of the $\mathrm{Cu}$ line increased by about $20 \mathrm{~nm}$. There was no difference in the depth of dishing whether an Ag-ion-based slurry was used or not at the second step of CMP. This implies that the relatively thin Ag layer was formed because the majority of the formed Ag layer was polished away by mechanical abrasion. Therefore, the decrease in the formation thickness of the Ag layer at the second step of CMP results in diminishing oxidation resistance (Fig. 4).

Ag capping is expected to have better chemical resistance during the cleaning or etching process due to its noble character compared to copper. The chemical resistance of the Ag film against SC-1 cleaning $\left(\mathrm{NH}_{4} \mathrm{OH}-\mathrm{H}_{2} \mathrm{O}_{2}-\mathrm{H}_{2} \mathrm{O}\right.$ mixture $)$ and a dry etching condition of tetraethoxysilane oxide were tested, and there was no obvious damage on the Ag surface morphology by FESEM. The results strongly suggest that the $\mathrm{Ag}$ capped $\mathrm{Cu}$ film has better process windows in many postcleaning or patterning processes. 


\section{Conclusions}

In this work, methods for the prevention of $\mathrm{Cu}$ oxidation and restoration of $\mathrm{Cu}$ dishing were developed. These methods are suitable to the damascene process, and they require no additional process step. The in situ formation of an $\mathrm{Ag}$ layer was attempted through the displacement reaction between the $\mathrm{Cu}$ surface and the $\mathrm{Ag}$ ions at the second step of CMP or at the buffing step during the $\mathrm{CMP}$. The $\mathrm{Cu}$ wafer with the $\mathrm{Ag}$ capping layer showed superior oxidation resistance when compared to pure- $\mathrm{Cu}$ wafer because the $\mathrm{Ag}$ layer effectively hindered the contact between oxygen and $\mathrm{Cu}$. Moreover, because the amount of the formed Ag film due to the displacement reaction is about 2.26 times larger than that of the consumed $\mathrm{Cu}$, the depth of $\mathrm{Cu}$ dishing in this experiment was reduced to about $20 \mathrm{~nm}$ regardless of the linewidth.

\section{Acknowledgments}

This research was supported by the Nano R\&D program through the Korea Science and Engineering Foundation (KOSEF) funded by the Ministry of Education, Science and Technology (2008-02857) and by the Fundamental R\&D Program for Core Technology of Materials funded by the Ministry of Commerce, Industry and Energy, Republic of Korea.
Seoul National University assisted in meeting the publication costs of this article.

\section{References}

1. S. P. Murarka, R. J. Gutmann, A. E. Kaloyeros, and W. A. Lanford, Thin Solid Films, 236, 257 (1993).

2. T. J. Licata, E. G. Colgan, J. M. E. Harper, and S. E. Luce, IBM J. Res. Dev., 39, 419 (1995).

3. A. Sethuraman, J.-F. Wang, and L. M. Cook, J. Electron. Mater., 25, 1617 (1996).

4. P. J. Ding, W. Wang, W. A. Lanford, S. Hymes, and S. P. Murarka, Nucl. Instrum. Methods Phys. Res. B, 85, 260 (1994).

5. X. Q. Zhao, Y. F. Han, and B. X. Liu, J. Appl. Phys., 90, 1638 (2001).

6. S. Hymes, S. P. Murarka, C. Shepard, and W. A. Lanford, J. Appl. Phys., 71, 4623 (1992).

7. S. Y. Chang, C. C. Wan, Y. Y. Wang, C. H. Shin, M. H. Tsai, S. L. Shue, C. H. Yu, and M. S. Liang, Thin Solid Films, 515, 1107 (2006).

8. J. Gambino, J. Wynne, G. Gill, S. Mongeon, D. Meatyard, B. Lee, H. Bamnolker, L. Hall, N. Li, M. Hernandez, et al., Microelectron. Eng., 83, 2059 (2006).

9. P. J. Ding, W. A. Landford, S. Hymes, and S. P. Murarka, J. Appl. Phys., 75, 3627 (1994)

10. W. A. Lanford, P. J. Ding, W. Wang, S. Hymes, and S. P. Murarka, Thin Solid Films, 262, 234 (1995).

11. J. J. Kim, Y. S. Kim, and S.-K. Kim, Electrochem. Solid-State Lett., 6, C17 (2003)

12. J. W. Lee, M. C. Kang, and J. J. Kim, J. Electrochem. Soc., 152, C827 (2005)

13. Y. Morand, Microelectron. Eng., 50, 391 (2000).

14. K. W. Chen, Y. L. Wang, C. P. Liu, L. Chang, and F. Y. Li, Thin Solid Films, 498, 50 (2006). 